\title{
Black Mirror e o espetáculo revisitado: um estado da
} arte e algumas reflexões

\author{
Black Mirror and the revisited spectacle: a state of the art \\ and some reflections
}

Black Mirror y el espetáculo revisitado: un estado del arte

y algunas reflexiones

\author{
MONICA FANTIN ${ }^{\mathrm{a}}$ \\ Jose Douglas Alves dos SANTOS ${ }^{\mathrm{b}}$ \\ KARINE JOULIE MARTINS ${ }^{c}$
}

\section{Resumo}

Este artigo discute aspectos da série de televisão britânica Black Mirror, criada por Charlie Brooker em 2011 - e no ar desde então -, com enfoque nas áreas da Educação e Comunicação e apresenta um estado da arte. O intuito é tensionar alguns temas e revisitar certos conceitos a partir de um mapeamento das produções acadêmicas sobre esta série no Brasil até o momento, a partir das seguintes fontes pesquisadas: o Portal brasileiro de publicações científicas em acesso aberto (oasisbr); o Portal de Livre Acesso à Produção em Ciências da Comunicação (Portcom); o Repositório Institucional da Universidade Federal de Santa Catarina (RI/UFSC); a Biblioteca Digital Brasileira de Teses e Dissertações (BDTD); e o Catálogo de Teses e Dissertações da CAPES. A análise dos dados sugere que a série vem ganhando destaque no cenário acadêmico brasileiro, e a partir da ideia de espetáculo revisitado, o texto tece algumas considerações sobre alguns temas recorrentes acerca dos usos das novas tecnologias digitais e das relações sociais mediadas por dispositivos complexos no contemporâneo - uso e controle das

\footnotetext{
a Universidade Federal de Santa Catarina, Florianópolis, Santa Catarina, SC, Brasil. Doutora em Educação, e-mail: monica.fantin@ufsc.br

b Universidade Federal de Santa Catarina (UFSC), Florianópolis, Santa Catarina, SC, Brasil. Mestre em Educação, e-mail: jdneo@hotmail.com

c Universidade Federal de Santa Catarina (UFSC), Florianópolis, Santa Catarina, SC, Brasil. Mestre em Educação, e-mail: karinejoulie@gmail.com
} 
mídias, vigilância e estruturas de poder, desumanização, cegueira moderna, relações sociais contemporâneas -, discutidos a partir de um ou mais episódios da série. A partir de um dos fios condutores nas diversas tramas, a crítica ao uso distorcido da tecnologia que parece cada vez mais assemelhar-se a aspectos da realidade, o texto discute a ideia de espetáculo de modo a atualizar a relação entre coisa, imagem e sujeito a partir de novos modos de sentir no contemporâneo.

Palavras-chave: Black Mirror. Estado da Arte. Produção acadêmica. Tecnologias digitais.

\section{Abstract}

This article discusses aspects of the British television series Black Mirror, created by Charlie Brooker in 2011 - and on the air ever since - focusing on Education and Communication study areas. The objective is to approach some topics and revisit certain concepts. For this purpose it is used a mapping of academic productions about this TV series in Brazil until now from the following sources: Brazilian open access portal of scientific publications (oasisbr); Free Access Portal to Communication Science Production (Portcom); Universidade Federal de Santa Catarina Institutional Repository (RI/UFSC); Brazilian Thesis and Dissertations Digital Library (BDTD); and the CAPES Thesis and Dissertations catalog. The data analysis suggests the TV series has become a relatively popular object of study in Brazilian academic scenario. On the concept of the spectacle, the text presents some considerations about recurring themes on the uses of new digital technologies and social relations mediated by complex apparatuses nowadays. Such as media use and control, surveillance and power structures, dehumanization, modern blindness, contemporary social relations - noticed from one or more episodes of the TV series. The text discusses the idea of spectacle to actualize the relation between thing, image, and subject from new ways of feeling in the contemporary following one of the guiding threads in the various plots the critique of the distorted use of technology that seems increasingly resembling aspects of reality.

Keywords: Black Mirror. State of the Art. Academic Production. Digital Technologies.

\section{Resumen}

Este artículo aborda aspectos de la serie de televisión británica "Black Mirror", creada por Charlie Brooker en 2011 - y que aún se transmite-, desde el enfoque de las áreas de la Educación y la Comunicación. El objetivo fue discutir algunos temas y revisar ciertos conceptos a partir de un mapeo de las producciones académicas brasileñas que analizan la serie hasta la fecha, a partir de las siguientes fuentes de investigación: el Portal Brasileño de Publicaciones Científicas de Acceso Abierto (OASISBR*); el Portal de Acceso Libre a la Producción Académica en Ciencias de la Comunicación (PORTCOM*); el Repositorio Institucional de la Universidad Federal de Santa Catarina (RI/UFSC*); la Biblioteca Digital Brasileña de Tesis y Disertaciones (BDTD*); y el Catálogo de Tesis y Disertaciones de la 
Coordinación para el Mejoramiento de Personal en Nivel Superior (CAPES*). El análisis de los datos sugiere que la serie está ganando destaque en el escenario académico brasileño y, desde la idea de espectáculo, el texto teje algunas consideraciones sobre temas recurrentes acerca de las nuevas tecnologías digitales y las relaciones sociales mediadas por dispositivos complejos. Algunos de los temas discutidos a partir de uno o más episodios de la serie son: el uso y control de los medios de comunicación, la vigilancia y estructuras de poder, deshumanización, ceguera moderna, relaciones sociales contemporáneas, entre otros. A partir de uno de los hilos conductores en las diversas tramas, la crítica al uso distorsionado de la tecnología - cada vez más parecido con la realidad -, el texto discute la idea de espectáculo, con el objetivo de actualizar la relación entre objeto, imagen y sujeto, a partir de nuevos modos de sentir en el contexto contemporâneo.

Palabras clave: Black Mirror. Estado del Arte. Producción académica. Tecnologías digitales.

\section{Notas Introdutórias}

Neste artigo buscamos situar aspectos da série de televisão britânica Black Mirror, criada por Charlie Brooker em 2011 e no ar até o presente momento e trazer alguns elementos da série, como informações relacionadas à sua origem e aos temas que seus episódios, hoje divididos em quatro temporadas, tratam. Isso permitirá um maior conhecimento sobre a série em si, antes de ter acesso às publicações encontradas que configuram o estado da arte desenvolvido. A elaboração dessa revisão sistemática de trabalhos que abordam a série tem o intuito de perceber o alcance desta produção no cenário acadêmico, em especial nas áreas da Educação e da Comunicação, reconhecendo os temas mais recorrentes que vêm sendo tratados pelas publicações brasileiras. Encerramos nosso texto trazendo algumas considerações sobre a série, os trabalhos elencados e as possíveis contribuições que os mesmos trazem às áreas referidas, visto que estamos diante de uma produção audiovisual de grande relevância no cenário contemporâneo. Desse modo, os discursos e narrativas sobre a sociedade que a série traz merecem e precisam ser conhecidos e problematizados para uma melhor compreensão daquilo que ela apresenta e representa. Assim, esperamos contribuir com essa síntese de pesquisas e com algumas elaborações filosóficas que a série nos permite construir. 


\section{Black Mirror: vertigens (a)temporais e sua relação}

\section{com a tecnologia}

Black Mirror é uma série britânica de drama, ficção científica e thriller, que apresenta questões e problemáticas associadas à sociedade contemporânea, tendo como fio condutor a relação estabelecida entre os seres humanos e as novas tecnologias no cotidiano. Seu formato antológico lembra a série "Além da Imaginação" (The Twilight Zone, 1958, de Rod Serling), trazendo enredos, cenários e personagens novos a cada episódio, que aparentemente não coabitam uma mesma realidade ${ }^{1}$. Cada episódio promove reflexões sobre "o lado sombrio e algumas vezes angustiante das relações e do comportamento dos humanos resultantes da incorporação de inovações tecnológicas ao cotidiano” (MAGNONI; BRESSAN; SILVA, 2016 p. 643).

Produzida pela Zepotron, uma produtora de conteúdo audiovisual do grupo econômico holandês Endemol Shine - detentor dos direitos autorais das mais conhecidas franquias de realities shows, tais como Big Brother e Masterchef - a série foi exibida inicialmente na Inglaterra pela rede Channel 4. Mas obteve maior reconhecimento quando disponibilizada no catálogo da Netflix, que em 2015 encomendou mais 12 episódios. Charlie Brooker, criador de Black Mirror, além de roteirista é comentarista e apresentador, que tem em sua carreira alguns trabalhos que satirizam a própria televisão. Estilo que também se faz presente em muitos episódios da série, como no piloto Hino Nacional² (The National Anthem, 2011, de Otto Bathurst, S01E01).

\footnotetext{
${ }^{1}$ Desde o início da série, em 2011, os fãs produziram teorias elecando easter eggs elementos que poderiam conectar cenários, tempos e personagens nos episódios - o que se concretiza no último episódio da quarta temporada, Black Museum (Colm McCarthy, 2017, S04E06). Nele uma personagem visita um museu num lugar ermo que guarda objetos que estiveram em cenas de crimes. Enquanto visita o espaço, o dono do museu conta a história dos objetos através de flashbacks que mostram sua conexão com o enredo de outros episódios da série.

${ }^{2} \mathrm{O}$ piloto tem como premissa o sequestro da princesa do Reino Unido e a condição para sua liberdade é um ato sexual televisionado entre o primeiro-ministro e um porco. À medida que o vídeo com a tal condição se espalha rapidamente pela internet, tem início
} 
"If technology is a drug — and it does feel like a drug — then what, precisely, are the side-effects?"3, provocou Brooker ao apresentar a série ao The Guardian, em 2011. Parte da sua experiência de receio e deslumbramento com o acelerado aparecimento de tecnologias nos dispositivos móveis servem para minimizar certos esforços cotidianos diante de aplicativos que simulam ações humanas, como por exemplo, assistentes de vOz em carros, smartphones e outros.

O gesto de dar ordens a um smartphone concretiza um futuro previsto na ficção científica produzida num passado recente, como quando em Os Jetsons (Joseph Barbera e William Hanna, 1962), George e Jane dão ordens à robô doméstica. Este é um dos grandes diferenciais entre Black Mirror e a as produções de ficção científica dos anos 1960 a 1990, que se pautam na relação humano-tecnologia. Enquanto o grande atrativo de uma miríade de filmes e séries desse gênero é justamente a profetização de máquinas miraculosas como os veículos voadores populares, a obra criada por Brooker parte da extrapolação do desenvolvimento de algumas premissas da tecnologia ou do pensamento/comportamento tecnológico no tempo presente, promovendo reflexões sociológicas e filosóficas sobre suas possíveis consequências para a humanidade.

São poucos os episódios que trazem elementos visuais de uma perspectiva de futuro cronológico. Dentre estes, podemos citar Quinze Milhões de Méritos (Fifteen Million Merits, 2011, de Euros Lyn, S01E02), que apresenta uma sociedade panóptica ocupando um espaço completamente fechado e compartimentado, onde as pessoas trabalham pedalando para gerar energia que mantém as telas (presentes em todos os espaços) ligadas por tempo integral. Para desligá-las durante o período de descanso é necessário ter merits, uma moeda virtual gerada com a distância pedalada. O enredo do episódio é centrado no desejo de ascensão de uma ciclista em se tornar cantora.

uma desesperada corrida oficial pela contenção do escândalo enquanto as redes de televisão pressionam o chefe de estado para cumprir a condição, grupos de defesa dos animais protestam e a população acompanha como a uma Copa do Mundo.

3 "Se a tecnologia é como uma droga - e ela parece com uma droga - quais são precisamente os efeitos colaterais?" <https://www.theguardian.com/technology/2011/dec/01/charlie-brooker-dark-side-gadgetaddiction-black-mirror>. 
A única oportunidade para esse movimento está na compra de um passaporte para participação em um programa de calouros que custa 15 milhões de merits.

Neste episódio, figurinos e cenários de um cotidiano "sem autenticidade" — como a própria personagem classifica - trazem características de uma ordem voltada apenas ao trabalho, uma premissa do período da industrialização, mas com cores e um estilo "limpo" e asséptico que remetem a laboratórios de experiência científica, tal como o que encontramos no filme "A Ilha" (The Island, 2005, de Michael Bay e Sylwia Kubus). Nesse sentido, o professor e pesquisador André Lemos avalia que os temas centrais abordados em Black Mirror - que relacionam cultura, tecnologia e sociedade — trazem uma reflexão mais pautada no passado e presente do que em projeções para o futuro. Segundo o autor, a série "apenas tangencia as questões cruciais dessas primeiras duas décadas do século XXI, não nos ajudando muito a pensar o presente e o futuro" (LEMOS, 2018, p. 15).

Embora possamos questionar em que medida nos ajuda ou não a pensar o presente mas também em diálogo com esta perspectiva, podemos pensar a série num nível de diagnóstico ou como um laboratório social a partir do qual o uso de um dispositivo tecnológico digital desencadeia certos comportamentos, sem apresentar desdobramentos ou possíveis caminhos. Portanto, destacamos o episódio Momento Waldo (The Waldo Moment, 2013, de Bryn Higgins, S02E03) no qual o personagem animado, Waldo, dublado por um ator desconhecido, fica conhecido por humilhar um ex-ministro da Cultura em entrevista na televisão. Pela repercussão que seu comportamento descontente com a política gera na internet, o personagem vai concorrer nas eleições para primeiro-ministro. O personagem é irônico e, sem apresentar proposta alguma, conquista o público por ser "algo novo" e não um "político profissional".

Em situações como a exposta neste episódio, Black Mirror adiciona um alerta à ideia de que a popularização do acesso às tecnologias digitais da informação e comunicação podem ser uma forma de promover produção e participação do público, como sugere, por exemplo Henry Jenkins (2009). Pois, uma vez que a tecnologia é produzida dentro das mesmas condições econômicas e culturais que 
delineiam nossas relações sociais, tal produção e participação não estão livres destas condições. A exemplo disto, cresce a importância da reflexão sobre as redes sociais, sobretudo diante do significativo impacto no resultado das últimas eleições nos Estados Unidos (2016) e no Brasil (2018), fenômeno discutido por jornalistas e pesquisadores da sociologia, comunicação, tecnologia, em diferentes países.

É cada vez mais frequente a citação de alguns episódios ou de determinadas situações evidenciadas na série, para relacionar ou exemplificar algum tema ou questão debatida em ambientes formativos institucionalizados. Dessa forma, Black Mirror consolidou-se também "como uma expressão no vocabulário popular, utilizada para se referir a fatos relacionados à presença de um aparato tecnológico potencialmente distópico, ao afirmar-se que tal tecnologia ou a situação promovida por ela é "muito black mirror" (VINHAS, 2018, s/p). Para André Lemos, o uso desta expressão "descreve o estranhamento, o incômodo e, às vezes, a sensação de pavor, medo ou asco, quando encontramos similaridades entre as histórias contadas na série e a nossa relação com as atuais tecnologias digitais de comunicação e informação" (2018, p. 14).

Devido a esta tese, oposta à maioria daquelas desenvolvidas por quem acompanha a série, Lemos sustenta que a expressão "isso é muito Black Mirror" deveria, na verdade, ser analisada sob outro ponto de vista, uma vez que, para ele, a série "fala do passado, vê o presente de forma distorcida pelo retrovisor e mal consegue antever o futuro” (2018, p. 16). Desse modo, “a expressão deveria ser ‘isso’ NÃO é muito Black Mirror', sendo ‘isso’ a nossa atual cultura digital’ (idem).

A repercussão da série demonstra o interesse que as relações sociais mediadas por dispositivos complexos provocam:

o sucesso que foi alcançado e a abrangência de suas narrativas, que em grande medida relacionam-se diretamente a temáticas estudadas e debatidas em distintos campos e áreas do saber. Cabe ressaltar que poucas produções para a televisão têm um discurso político tão inteligente e bem articulado como Black Mirror. Entre as histórias vemos críticas às mídias sociais, à exposição da vida privada, à amizade virtual, à futilidade dos pertences virtuais, ao esvaziamento dos indivíduos e ao desmedido processo civilizatório que acomete cada vez a sociedade contemporânea e que nos levam a pensar nesta realidade em que vivemos e em 
como será nosso futuro devido a essa dependência (OLIVEIRA; NASCIMENTO; SCHYRA, 2014, p. 29).

Afinal, são muitas e múltiplas as possibilidades de estudo e análise em relação a essa série que "pode ser examinada sob outras perspectivas (jurídica, psicológica, econômica, entre outras" (LEMOS, 2018, p. 16). E isso nos leva a tecer alguns fios condutores e a buscar outros diálogos.

\section{Fios condutores e diálogos possíveis}

Como mencionado antes, a produção britânica mudou o panorama de séries televisivas nos últimos dez anos, uma mistura de ficção científica com terror, sua "marca" faz referência ao chamado "efeito Black Mirror", provocando as mais diversas reações entre espectadores perplexos e, por vezes, perturbados, mas nunca indiferentes diante de uma realidade entre progresso e distopia de seus episódios. Inicialmente ambientada numa espécie de "futuro", para alguns estudiosos a série concentra-se fortemente nos problemas da atualidade. Para outros como Lemos (2018), a realidade da nossa atual cultura digital em nada se parece com as da série, não apenas porque o futuro ainda não chegou, mas porque, segundo ele, a série fala mais do passado que do presente: "apresenta tecnologias novas com roupagens velhas, olhando o presente pelo retrovisor, repetindo análises que foram próprias a uma crítica da sociedade tecnocientífica do século XX” (2018, p. 16), e ainda de acordo com Lemos, os problemas colocados pela cultura digital hoje estariam à frente dos expostos na série.

De qualquer modo, sabemos que as relações entre presente-passado-futuro se constroem, se projetam e se modificam conforme os significados que a elas atribuímos, e superados ou não, nos deparamos com alguns temas da série que permanecem e ainda ecoam em nosso cotidiano, como por exemplo, a dependência e a obsessão que o progresso tecnológico estimula na sociedade contemporânea. Além disso, é possível ainda identificar certos temas recorrentes na série, como a ideia de espetáculo (DEBORD, 1997), de extimidade (TISSERON, 2011), do "show 
do eu" (SIBILIA, 2008), as mídias sociais (LEMOS, 2018), o corpo artificial (SANTAELLA, 2008), a cultura da conexão (JENKINS; GREEN; FORD, 2014), o controle, a vigilância nas telas e nas redes (HAN, 2015), e as relações entre utopias e distopias (FLUSSER, 2007, 2008, BIANCHETTI e THIESEN, 2014). Ou seja, [quase] tudo o que pode ser feito com os dispositivos eletrônicos e digitais mostrado nas telas provoca certo tipo de choque e de alguma forma desestabiliza aquilo que se considerava "normal".

Entre as dimensões éticas, estéticas, políticas no contemporâneo, a estética parece "despedaçar" certas noções e não ser mais reduzível a uma imagem coerente, diz Perniola (2011) e a partir de quatro campos conceituais da estética vida, forma, conhecimento, ação — o autor identifica algumas linhas de reflexão. Interessa-nos particularmente a estética do sentir, que entre outros aspectos envolve ver algo "como algo", persuasão e estranhamento e a ideia do sex appeal do inorgânico, aliado a uma forte emoção ou até mesmo à ideia de choque, no sentido benjaminiano.

Assim, consideramos importante não apenas repetir análises e críticas feitas à sociedade tecnocientífica do século XX, mas recuperá-las em sua potência e atualizálas aos desafios que hoje se apresentam. Afinal, se por um lado é inegável e fundamental a presença irreversível das novas tecnologias, não parece ser menos importante manter na pauta de discussão suas formas mais tradicionais, diz Caldas (In PERNIOLA, 2005, p.10) ao apresentar a reflexão filosófica que pode contribuir para o conhecimento e transformação de nossa contemporaneidade tecnológica. Segundo Perniola, estamos diante do desafio de "analisar a existência de novas materialidades-orgânicas e de inorganicidade-vivas, que transitam na fronteira entre "coisa" e a "imagem", entre a "imagem e o sujeito" (2005, p. 17).

E nas fluidas fronteiras entre coisa, imagem e sujeito por meio de choques que vemos nas telas e particularmente em algumas séries, Debord (1997) nos ajuda na compreensão desse espetáculo revisitado que ainda pode coincidir com a compreensão da própria sociedade. Para o autor, é no espetáculo que se provoca a alienação, e não mais na opressão da luta de classes ou no fetichismo da mercadoria, 
pois as imagens e o aparecer começaram a se tornar onipresentes e a ter um poder sobre o mundo de maneira diferente, considerando que o espetáculo não diz respeito apenas a um conjunto de imagens, mas sobretudo a uma relação social entre indivíduos mediados por elas.

Tal poder se potencializou na cultura digital agregando outros aspectos, e Black Mirror mostra personagens que vivem experiências — da imagem, do espetáculo, do digital, da hiperconexão e do corpo artificial - de formas diferentes: circundados em telas, vítimas de um sistema judiciário transformado em espetáculo de justiça, ou prisioneiros de índices de preferência/afeição determinados por pontos dados pelas pessoas por meio de smartphone, só para mencionar exemplos de alguns episódios: Quinze Milhões de Méritos; Urso Branco (White Bear, 2013, de Carl Tibettis, S02E02); e Queda Livre (Nosedive, 2016, de Joe Wright, S03E01).

Se é quase senso comum que hoje não seria mais possível viver uma vida desconectada, o episódio Queda Livre agudiza essa “impressão de realidade" mostrando uma sociedade estruturada em torno de perfis sociais hiperconetados e de uma hipocrisia onipresente. A icônica personagem Lacie exibe uma ação velada de falsas e forçadas gentilezas só para aumentar os pontos e o próprio índice de preferência, simbolizando como ninguém mais estaria livre para ser verdadeiramente o que é. Ou talvez, o próprio ser se reduziria a isso mesmo: a pessoa é ou equivale os pontos que ganha e perde a partir do olhar e julgamento do outro. Na obsessão da ideia de ser popular, a personagem descobre que para ter um desconto na compra de um apartamento, necessita pelo menos 4,5 pontos, e para tal reata a amizade com uma amiga de infância muito popular e famosa influencer. Bem ao estilo debordiano, a imersão de Lacie no espetáculo a torna “vazia" e esta condição insustentável culmina em uma explosão nervosa no casamento da amiga. Assim, ela vive o desgaste tanto de ser ela mesma como de ser alguém que não é. O espetáculo não apenas definiu sua persona e seu desejo, mas a aprisionou de si própria e só quando é forçada a se retirar do espetáculo e está presa em uma cela, reencontra sua autenticidade trocando insultos com a prisioneira da cela em frente. 
As relações construídas com os próprios smartphones e aplicativos têm propiciado outros tipos de interação, e como nossas relações são mediadas também por imagens, na sociedade atual elas são produzidas por nossos próprios celulares. Segundo Debord (1997), quanto mais vemos nossa vida com as lentes do espetáculo, menos somos capazes de compreender nossa existência e nossos desejos.

Mas como chegamos a criar esta condição? Como o espetáculo e a hiperconexão consegue "subtrair" parte/ou o melhor da vida de Lacie, e por vezes das nossas próprias vidas? Como ela e nós mesmos permitimos isso? Para além do determinismo da tecnologia e do binômio realidade-ficção, parece que Debord (1997) pode nos dar uma resposta que também está presente em Black Mirror quando reflete sobre o fato de que o espetáculo nasce quando a economia invade completamente a estrutura de nossa vida social. E se este domínio da economia foi possível no momento em que começamos a ser definidos pelo ter ou pela aparência, para além da dimensão de pertencimento, Black Mirror eleva esse conceito em um outro nível.

É bom lembrar que quando Debord (1997) escreveu $A$ sociedade do espetáculo o mundo era apenas dominado pela capilaridade da mídia como a televisão, o rádio, o cinema e a publicidade. Embora não tenha previsto ou imaginado a chegada das mídias sociais, das tecnologias digitais e dos dispositivos complexos, ele parece ter intuído profeticamente como a sociedade mudaria radicalmente nos seus valores e significados com a cultura digital. Nesse sentido, Black Mirror nos provoca a pensar: o espetáculo, as mídias sociais, as redes, a hiperconexão e outros dispositivos da tecnologia digital nos conduð̨irão a uma distopia? Ou já vivemos nela?

Enfim, essas e outras inquietações nos levam a pensar e questionar sobre o alcance da série a nível de publicações acadêmicas no Brasil, justificando a realização de um estado da arte que possibilite um mapeamento dos trabalhos produzidos até o momento.

Salientamos que não temos a intenção de aprofundar discussões sobre a estrutura, narrativa e análises dos episódios neste momento. O enfoque que 
estabelecemos é o de identificar os trabalhos produzidos a partir da série e publicados em determinados bancos de dados brasileiros e atentarmos aos temas mais recorrentes que estes trazem, fazendo um levantamento histórico e bibliográfico e sistematizando os dados obtidos. Deste modo, retomaremos algumas considerações a respeito mais adiante.

\section{Um estado da arte em construção}

Em nossa trilha investigativa recorremos a alguns bancos de pesquisas para a concretização deste trabalho. São eles: o Portal brasileiro de publicações científicas em acesso aberto (oasisbr); o Portal de Livre Acesso à Produção em Ciências da Comunicação (Portcom); o Repositório Institucional da Universidade Federal de Santa Catarina (RI/UFSC) — para termos uma base de possíveis publicações locais; a Biblioteca Digital Brasileira de Teses e Dissertações (BDTD); e o Catálogo de Teses e Dissertações da CAPES.

Estes bancos e suas respectivas plataformas serviram de base para a obtenção dos dados propostos. O critério estabelecido para considerá-los em relação a outros que poderiam também fazer parte de nosso procedimento metodológico diz respeito ao fato de serem repositórios nacionais de grande relevo na sociedade acadêmica, reconhecidos entre os pares como alguns dos mais confiáveis e de melhor indexação.

Porém, antes de trazermos os dados referentes às publicações encontradas, em um primeiro momento fazemos uma breve apresentação e reflexão sobre o desenvolvimento de um estado da arte, no intuito de situar este exercício metodológico que busca revisar sistematicamente trabalhos produzidos sobre determinado tema, o que contribui para a solidificação de um trabalho científico.

As publicações são apresentadas e organizadas logo em seguida, dando destaque aos temas retratados e à discussão empreendida em cada um dos trabalhos selecionados nos bancos de dados pesquisados. Desde artigos, trabalhos de conclusão de curso, uma dissertação e uma tese, a série, propulsora de discussões 
(FAQUIN, 2018), vem inspirando a produção de diferentes estudos e reflexões que contribuem para (re)pensar questões associadas às áreas da Educação e da Comunicação no contexto acadêmico.

Como procedimento metodológico, o estado da arte é uma etapa necessária e essencial para o desenvolvimento de toda investigação acadêmica qualificada, pois contribui na catalogação de dados que servirão de referência não somente para quem realiza sua pesquisa, mas também para futuros pesquisadores que trabalharão com problemas semelhantes.

Divisor de águas para muitas pesquisas acadêmicas, e agregador de dúvidas para muitos iniciantes no campo do trabalho científico, o estado da arte é um processo investigativo que requer cuidados e uma certa dose de paciência para aqueles que não estão muito acostumados com esse tipo de tarefa. Essencial para o desenvolvimento de qualquer estudo, ele é considerado o ponto de partida no processo de elaboração das pesquisas acadêmicas.

"Não se faz pesquisa em uma área sem se conhecer minimamente o que é produzido, quais são os temas discutidos, que problemáticas são pesquisadas, quais abordagens são utilizadas nos estudos" (LAZZARIN, 2017, p. 15). Por isso atribuise tanto valor ao processo de revisão sistemática dos trabalhos já realizados sobre determinada questão, pois desenvolve-se uma espécie de mapa em que é possível acessar os principais lócus de incidência dos debates na área, os referenciais mais utilizados e conhecidos, bem como aqueles trabalhos/autores que possuem menos visibilidade.

Ao reunir e elencar trabalhos realizados que dialogam com o tema proposto, o estado da arte, também conhecido como estado do conhecimento - e, por vezes, (con)fundido como revisão de literatura - contribui para melhor situar o/a pesquisador/a dentro daquele território que se pretende explorar, tanto para aprofundar sua pesquisa, como para repensar questões outrora colocadas sobre a mesma. Ao perceber que alguns pontos já foram tratados e abordados, pode-se estabelecer novos critérios de estudo para não trilhar caminhos já percorridos e 
conhecidos, o que permite vislumbrar novas possibilidades para a produção de um trabalho que não seja considerado mais do mesmo.

Estados da arte podem significar uma contribuição importante na constituição do campo teórico de uma área de conhecimento, pois procuram identificar os aportes significativos da construção da teoria e prática pedagógica, apontar as restrições sobre o campo em que se move a pesquisa, as suas lacunas de disseminação, identificar experiências inovadoras investigadas que apontem alternativas de solução para os problemas da prática e reconhecer as contribuições da pesquisa na constituição de propostas na área focalizada (ROMANOWSKI; ENS 2006, p. 39).

Até meados da década de 1980, o estado da arte, ao menos sua terminologia, não fazia parte do vocabulário científico da maior parte dos pesquisadores brasileiros (BRANDÃO; BAETA; ROCHA, 1983), sendo incorporado de modo literal da tradução inglesa (tateoftheart), significando um diagnóstico de algo (RIBEIRO; CASTRO, 2016). De modo geral, ele serve como um diagnóstico do caso a ser abordado, dando aos pesquisadores um panorama abrangente sobre sua problemática de estudo, fazendo-os aprofundar suas questões ou orientando-os a delinear novas perguntas, procedimentos metodológicos e/ou abordagens teóricas.

Segundo Sílvia Nóbrega-Therrien e Jacques Therrien, o estado da arte serve como um "inventário descritivo da produção acadêmica e científica sobre o tema investigado" (2004, p. 8), o que, ainda de acordo com os autores, permitirá aos pesquisadores identificar o referencial de análise dos dados em sua revisão de literatura — aqui dissociada do estado da arte como processos distintos.

Todavia, é mais comum ver o estado da arte associado à revisão de literatura como processos similares, quase como sinônimos, sem o entendimento de que ele seja, na verdade, um dos objetivos da revisão de literatura, que se refere a uma fundamentação teórica a ser adotada para tratar tanto do tema como do problema de pesquisa (SILVA; MENEZES, 2005). Neste sentido, o estado da arte, dentro da revisão de literatura, fornece o inventário da produção acadêmica e científica a que Nóbrega-Therrien e Therrien (2004) se referem.

Guardadas as devidas especificidades desses processos, o estado da arte se configura como elemento-chave para legitimar as pesquisas acadêmicas, 
contribuindo para que elas possam se estruturar e se organizar tendo uma base que demonstre a relevância não só do tema em si, mas também do próprio estudo a ser efetuado, a partir do quantitativo de produções outrora realizadas e que se aproximam de determinada questão.

Dessa forma, esse processo resulta ainda em um reconhecimento, daquilo que já fora feito sobre o mesmo assunto, ou sobre algo que se assemelhe à sua investigação, fazendo-os perceber que seu trabalho não é uma novidade em termos gerais e absolutos, e nem tampouco está começando — ou precisa começar — sua pesquisa do zero (MARCONI; LAKATOS, 1991).

Em outras palavras, o estado da arte contribui para que os pesquisadores encontrem, historicamente, os vestígios e rastros de outros estudiosos e teóricos que se debruçaram sobre o tema em si, em outros tempos e lugares, assegurando uma base sólida que os pesquisadores necessitam no contexto da pesquisa acadêmica.

Trata-se de um procedimento metodológico que ajuda a catalogar, organizar e operacionalizar dados que serão utilizados e que servirão de referência ao estudo que se pretende fazer, construindo assim essa base teórica sólida e qualificada quanto ao assunto a ser abordado. Destarte, este ajuda a mapear o campo teórico e a tecer as primeiras aproximações com outros estudiosos que trabalham ou tralharam com a temática.

De modo mais específico, existem pesquisas que incidem diretamente sobre o estado da arte e que o têm como base central de seus estudos, sendo considerado menos como um elemento complementar, ainda que essencial, da pesquisa realizada, e mais como um elemento preponderante teórica e metodologicamente. Neste caso,

O estado da arte é uma modalidade de pesquisa de caráter bibliográfico, que visa fazer uma síntese integrativa do conhecimento sobre um determinado tema, comumente a partir de teses e dissertações, mas que pode incluir artigos publicados em periódicos e até mesmo comunicações em anais de congressos e seminários. O desafio é mapear e discutir a produção acadêmica em determinado campo do conhecimento, buscando responder que aspectos vêm sendo destacados em diferentes épocas e lugares e de que formas e em que condições essa produção vem sendo engendrada (SANTOS, 2015, p. 41). 
Essa síntese integrativa do conhecimento sobre determinado tema é o que contribui para que os estudos realizados sejam considerados a partir de uma perspectiva histórica e bibliográfica, inserindo-se como uma nova referência para futuros pesquisadores que também pesquisarão na mesma área ou no mesmo campo a partir de um tema semelhante.

Para Norma Ferreira, os pesquisadores que traçam suas pesquisas tendo como elemento central o estado arte "são movidos pelo desafio de conhecer o já construído e produzido para depois buscar o que ainda não foi feito” (2002, p. 259). Dedicando assim mais atenção às pesquisas realizadas e de difícil acesso entre seus pares, buscam dar conta de um saber que aumenta de produção de modo cada vez mais veloz e que nem sempre é compartilhado socialmente ou tem uma expressividade e um reconhecimento social.

Tal como um arqueólogo que escava em diferentes regiões em busca de vestígios do passado, os pesquisadores também fazem suas escavações por meio da revisão de literatura, sobretudo a partir dos resultados obtidos com o estado da arte, buscando em distintas plataformas e ambientes aqueles trabalhos que poderão servir de fio condutor para os passos seguintes de seus estudos.

Os principais lugares de "escovação" dos pesquisadores no campo das ciências humanas e sociais costumam ser "os catálogos de faculdades, institutos, universidades, associações nacionais e órgãos de fomento da pesquisa" (FERREIRA, 2002, p. 259). Os bancos de teses e dissertações — virtuais ou presencialmente —, com suas bibliotecas setoriais são, neste sentido, os principais espaços de inserção dos pesquisadores quando estão começando suas investigações.

Ainda sobre os catálogos, Ferreira descreve que eles "permitem o rastreamento do já construído, orientam o leitor na pesquisa bibliográfica de produção de uma certa área" (2002, p. 261), e têm a vantagem, na maioria dos casos, de ser consultados em ordem alfabética, por assuntos, temas, autores, datas, áreas, programas, entre outros. Geralmente é a partir dos títulos e dos resumos que se articula uma primeira aproximação com os trabalhos já produzidos e o próprio 
trabalho, separando-os de acordo com categorias ou eixos que melhor definam e dialoguem com o que se procura.

Essa primeira aproximação, orientada por meios dos resumos encontrados de teses e dissertações, ajuda a quantificar os dados obtidos e a identificá-los, mas é após a leitura na íntegra desses trabalhos que se estabelecem os parâmetros qualitativos que incidirão sobre uma maior aproximação com o que se objetiva produzir posteriormente.

Diante desse "apanhado geral sobre os principais trabalhos já realizados" (MARCONI; LAKATOS, 1991, p. 68) que o estado da arte possibilita, dessa “síntese integrativa do conhecimento" (ANDRÉ et al., 1998 p. 301), descrevemos na sequência alguns dos procedimentos apontados por Romanowski (2002) em relação às pesquisas que utilizam do estado da arte, da qual utilizamos na escrita deste artigo. Entre alguns dos passos sugeridos, estão: definição dos descritores; localização dos bancos de pesquisas, os acervos de teses e dissertações, coleções de periódicos, etc.; estabelecimento de critérios para a seleção do material; leitura das publicações com elaboração de síntese; organização de relatório do estudo, identificando tendências temáticas e possíveis relações entre teses e dissertações; e análise e elaboração das conclusões preliminares.

Neste artigo, a utilização do descritor Black Mirror na opção de busca determinou o conjunto de textos a serem quantificados. A partir da definição do descritor, elencamos os bancos de pesquisa a serem acessados. Devido ao recorte geográfico proposto neste estado da arte - recorte de trabalhos em âmbito nacional -, utilizamos dos seguintes bancos de dados: o Portal brasileiro de publicações científicas em acesso aberto (oasisbr), gerido pelo Instituto Brasileiro de Informação em Ciência e Tenologia (Ibict/MCTI) e que utiliza de um mecanismo de busca multidisciplinar em relação à produção científica de universidades e institutos de pesquisas nacionais; o Portal de Livre Acesso à Produção em Ciências da Comunicação (Portcom), que em seu processo de busca traz dados de trabalhos em eventos, livros, capítulos de livros, enciclopédias e e-books; o Repositório Institucional da Universidade Federal de Santa Catarina (RI/UFSC); a Biblioteca 
Digital Brasileira de Teses e Dissertações (BDTD); e o Catálogo de Teses e Dissertações da CAPES.

Não houve estabelecimento de critérios para a seleção do material, uma vez que o tema da pesquisa pode ser considerado ainda recente e incipiente - o que descartou também um possível recorte temporal nos bancos de pesquisa, optandose por averiguar todos os trabalhos existentes sobre o assunto, até o presente momento ${ }^{4}$. Por meio da leitura dos trabalhos encontrados, pudemos identificar algumas tendências e perceber relações estabelecidas entre as publicações, o que os permitiu definir algumas conclusões preliminares, conforme pode ser encontrada ao fim do texto.

\section{Black Mirror: um estado da arte nas produções acadêmicas brasileiras}

Durante o processo de pesquisa nos bancos de dados selecionados, obtivemos o total de quatorze publicações cadastradas. Dessas, sete foram artigos publicados em periódicos; um apresentado em congresso; quatro trabalhos de conclusão de curso; uma dissertação; e uma tese. Convém salientarmos que nem todas as publicações sobre a série estão cadastradas nessas bases de dados, mas para o objetivo deste trabalho restringimo-nos às produções registradas.

No Portal brasileiro de publicações científicas em acesso aberto (oasisbr), encontramos sete artigos, quatro trabalhos de conclusão de curso e uma tese, publicados no período de 2016 a 2018, integrando em seu acervo boa parte dos estudos selecionados e descritos a seguir.

Entre os Trabalhos de Conclusão de Curso (TCC), Mariana Correa de Araújo (2016) faz algumas reflexões da série, tendo como enfoque o episódio Urso Branco. Intitulada "Parque da Justiça: reflexões jusfilosóficas e desumanização", sua monografia, apresentada na Faculdade de Direito da Universidade Federal de Juiz de

\footnotetext{
${ }^{4}$ Novembro de 2018.
} 
Fora (UFJF), utiliza conceitos de dois dos mais influentes pensadores desde o século passado, Walter Benjamin e Hannah Arendt, para pensar as relações entre violência, poder, degradação humana, injustiça e desumanização, além de promover uma reflexão sobre as relações sociais na contemporaneidade.

Paulo Edmundo Rodrigues Bettim (2017), por sua vez, na monografia/TCC "Percepşões sobre o conceito de hipermodernidade a partir do uso das telas do episódio "Queda livre" do seriado Black Mirror", apresentada no curso de Relações Públicas da Universidade Federal do Pampa (UNIPAMPA), em São Borja/RS, reflete sobre a noção de hipermodernidade e o uso de telas, bem como traz ponderações sobre o comportamento dos usuários. Como objeto de análise, Bettim tem os personagens de Black Mirror, do episódio Queda Livre, apontando percepções sobre a hipermodernidade desse episódio que reforçam situações cotidianas.

Também em 2017, Arthur Serra Carneiro dos Santos Xavier apresentou a monografia/TCC "Black Mirror - Nosedive: a influência da midiatização nas práticas sociais", na Faculdade de Tecnologia e Ciências Sociais do Centro Universitário de Brasília (UniCEUB), para o curso de Publicidade e Propaganda. Neste trabalho, Xavier discute as relações sociais contemporâneas mais uma vez a partir do episódio Queda Livre, trazendo questões relativas à midiatização, modernidade líquida e revolução digital para pensar as relações e o modo como os indivíduos se comportam em nossos dias e as consequências desse processo.

Já em "Narrativas distópicas: um estudo comparativo entre 1984 e a série Black Mirror", monografia/TCC realizada por Lisiane Cristina Bauer (2018) e apresentada no Instituto de Letras da Universidade Federal do Rio Grande do Sul (UFRGS), no curso de Letras, temos uma abordagem das semelhanças entre a obra "1984" de George Orwell com três episódios de Black Mirror - Quinze Milhões de Méritos; Urso Branco; e Queda Livre —, debatendo, a partir do gênero narrativo distópico, questões referentes a mecanismos de controle, vigilância, uso da tecnologia, estruturas de poder, entre outros.

Entre os artigos encontrados, Maria Visconti (2017), na Temporalidades Revista de História (UFMG), com o texto "Black Mirror e a cegueira moral na 
modernidade", analisa o episódio Engenharia Reversa (Men against fire, 2016, de Jakob Verbruggen, S03E05), relacionando-o às teorias de Zygmunt Bauman, e Hannah Arendt para discutir o Holocausto e a cegueira moral da sociedade moderna, que segundo a autora pode levar a novos processos de extermínio semelhantes, articulando-o com Pierre Rosanvallon e a história filosófica do político para refletir sobre os usos da história no tempo presente e o constante diálogo entre passado e presente.

Marcelo Santos da Rosa e Rosângela Fachel de Medeiros (2017), no artigo “A extrapolação das relações virtuais em Black Mirror”, publicado pela revista Literatura e Autoritarismo (UFSM) a partir dos episódios Volto Já (Be Right Back, Owen Harris, 2013, S02E01) e Queda Livre, buscam relacionar os personagens da série com a realidade atual no intuito de compreender os impactos das relações virtuais na vida das pessoas, imersas em ambientes digitais e em vivências mediadas por dispositivos tecnológicos.

"Modalizações do fazer no episódio "Hino Nacional”, do seriado Black Mirror", artigo de Conrado Moreira Mendes (2017) publicado na Significação - Revistas de Cultura Audiovisual (USP), analisa as modalizações do fazer no referido episódio, tendo como base analítica a semiótica greimasiana e sua teoria das modalidades. De acordo com o autor, o episódio consegue demonstrar como as modalizações, no contexto da cultura de convergência, podem alterar a competência modal do sujeito, dando ênfase ao papel das mídias e tecnologias no processo das relações sociais contemporâneas, bem como na propagação de quadros de valores.

Ainda em 2017, Dirce Vasconcellos Lopes, Nathalia Maciel Corsi, Denise Batista Sabino e Guilherme Popolin, no artigo "The entire history of you": Cibercultura e memória", publicado na revista Mediação (FUMEC), avaliam as influências da tecnologia sobre a memória humana no episódio Toda Sua Hstória (The entire history of you, 2011, de Brian Welsh, S01E03), partindo de uma discussão que toma como eixo gerador o avanço da cibercultura e a simbiose entre corpo e tecnologia como parte da vida real. 
Na revista Farol-Revistas de Estudos Organizacionais e Sociedade (UFMG), Bruno de Almeida Matos, Luana Jéssica Oliveira Carmo e Lilian Bambirra de Assis (2018), no artigo "Quantas estrelas você vale? Uma análise da gamificação em um episódio da série Black Mirror", analisam a relação entre modernidade, sociedade do consumo e gamificação no episódio Queda Livre, refletindo sobre outra face da gamificação que está atrelada à lógica da dominação do sujeito, transformando-o em um objeto/mercadoria.

Ana Paula de Souza, Luis Gustavo da Conceição Galego e Fernando Lourenço Pereiras (2018), no artigo "Análise semiótica e do discurso no episódio "Nosedive" da série Black Mirror: um olhar sobre a ética e as tecnologias da comunicação e informação", publicado na Revista Livre de Cinema (RELICI, publicação independente), realizam uma análise semiótica a partir de cenas do referido episódio que trazem questões envolvendo ética e o uso das tecnologias da comunicação e informação.

O artigo de Flávio Gomes de França (2018), “A 'distinção policial militar’: por uma compreensão da violência policial militar a partir da série Black Mirror", publicado na Dilemas - Revista de Estudos de Conflito e Controle Social (UFRJ), não foi possível ser acessado devido a algum problema técnico no site do periódico.

Quanto à tese, obtivemos como resultado o trabalho de Francisco Beltrame Trento (2017), "Espelhos negros: mutações do desejo e da crítica na comunicação", defendida no Doutorado em Comunicação e Semiótica da Pontifícia Universidade Católica (PUC/SP). Ao analisar como os novos ecossistemas e agenciamentos midiáticos que propiciam encontros (passivos e/ou ativos), fenômenos comunicativos — vêm modulando a produção de desejo nos indivíduos, Trento observa uma produção de desejo de controle que os dispositivos midiáticos proporcionam e incitam, bem como o desejo de emulação e imitação, e que são observados e problematizados nas primeiras duas temporadas de Black Mirror.

Estes foram os dados obtidos no Portal brasileiro de publicações científicas em acesso aberto (oasisbr). Ao realizarmos nossa consulta no Portal de Livre Acesso à Produção em Ciências da Comunicação (Portcom), obtivemos um trabalho apresentado em evento, no XVIII Congresso de Ciências da Comunicação na 
Região Sudeste, realizado em Bauru/SP. Trata-se do texto "Subjetividade, controle e ubiquidade midiatica: o seriado Black Mirror", de Francisco Beltrame Trento e Thiago Siqueira Venanzoni (2013), que apresenta reflexões sobre controle e ubiquidade midiática, além da construção de subjetividade nesse contexto, tendo o episódio Hino Nacional como base de análise.

Ao efetuarmos uma busca no Repositório Institucional da Universidade Federal de Santa Catarina (RI/UFSC), não identificamos nenhum trabalho cadastrado em relação a Black Mirror - aqui salientamos uma falha no sistema, uma vez que encontramos o artigo "Da melancolia à ironia: o discurso dissimulado da contemporaneidade em Black Mirror", escrito por Andréia de Oliveira, Danilo Nascimento e Geralda Schyra (2014), e publicado pela revista Texto Digital, vinculada à instituição. Fato este que também nos leva a relativizar certos dados obtidos, pois sabemos de trabalhos realizados sobre determinados temas que por vezes não aparecem nas bases de dados, seja pelo título/resumo/palavras-chave escolhidas ou por outros motivos.

Na Biblioteca Digital Brasileira de Teses e Dissertações (BDTD), nossa pesquisa identificou um estudo anteriormente encontrado no Portal brasileiro de publicações científicas em acesso aberto, a tese de Francisco Beltrame Trento (2017).

O Catálogo de Teses e Dissertações da CAPES, por sua vez, trouxe dois trabalhos, sendo um deles novamente a tese de Francisco Trento (2017) — já elencada a partir das pesquisas no oasisbr e no BDTD. Um novo trabalho a ser anexado às publicações sobre Black Mirror, e ainda não registrado nas outras plataformas, foi a dissertação de César Biégas Faquim (2018), intitulada “Black Mirror: cinema, televisão ou produto híbrido?”, defendida no Programa de Pós-Graduação em Comunicação e Linguagens, da Universidade Tuiuti do Paraná (UTP). Faquim propõe analisar conceitos que caracterizam hibridizações midiáticas, como os conceitos de dialogismo e polifonia, intertextualidade, intermidialidade e hipervenção, que contribuem, segundo o autor, para a compreensão dos processos de hibridizações, analisados por ele em Black Mirror, no período de 2011 a 2017 _ 
o que corresponde às primeiras quatro temporadas - e problematizado em consonância com o filme "1984”, de Michael Radford.

\section{Algumas considerações preliminares}

A partir de um mapeamento sobre a produção acadêmica a respeito de Black Mirror no Brasil foi possível identificar diversos temas emergentes, tais como o uso e controle das mídias, vigilância e estruturas de poder, desumanização, cegueira moderna, relações sociais contemporâneas, discutidos a partir de um ou mais episódios da série. Apesar de não trazer um número expressivo de trabalhos, o levantamento deixou claro que as discussões também partem e propõe diálogos interdisciplinares envolvendo as áreas da comunicação, direito, publicidade, literatura, história, filosofia e sociologia, demonstrando que sua discussão não se restringe à comunicação, meio em que geralmente se concentram às análises de objetos audiovisuais.

Ao situar alguns aspectos de Black Mirror, sugerimos como fio condutor nas diversas tramas a crítica ao uso distorcido da tecnologia que parece cada vez mais assemelhar-se a aspectos da realidade: dispositivos capazes de memorizar e rastrear tudo o que o indivíduo faz — ou deixa de fazer — , de clonar a personalidade de uma pessoa em outro corpo [artificial ou não], de controlar consciências, gestos e ações. Discutimos também algumas possibilidades a partir da ideia espetáculo como tema recorrente em episódios da série, de modo a atualizar a relação entre coisa, imagem e sujeito a partir da ideia de sex appeal do inorgânico e seus novos modos de sentir no contemporâneo. E aqui poderíamos perguntar até que ponto Black Mirror pode ser considerada como espelho, caricatura, (des)construção ou (de)formação da sociedade do espetáculo?

Talvez o desafio do projeto de Flusser (2007) e sua medialogia, nos ajude a pensar sobre a possibilidade de "nos projetarmos fora do projeto", ou pelo menos, fora deste projeto de sociedade que estamos vivendo hoje... 
Enfim, questões que inquietam e provocam o nosso pensar. Afinal, enquanto Lemos (2018) considera que a série trata mais do passado do que do presente e do futuro, os trabalhos encontrados demonstram que a produção pode ser um objeto promissor para mobilizar perguntas e debates a respeito, especialmente no que se refere às relações humanas. De certa forma, a "tela escura" - espectro de uma tela de televisão ou outra qualquer ao ser desligada — que nos é apresentada por Charlie Brooker é um meio de nos fazer admirar nosso próprio reflexo enquanto nos relacionamos com as telas ainda ligadas.

\section{Referências}

ANDRÉ, M.; et al. Estado da Arte da Formação de Professor no Brasil. Educação \& Sociedade. Campinas/SP, ano 20, n. 68, p. 301-309, dez.1998.

ARAÚJO, M. C. Parque da justiça: reflexões jusfilosóficas e desumanização. Monografia (curso de Direito) - Universidade Federal de Juiz de Fora, Juiz de Fora, 2016.

BAUER, L. C. Narrativas distópicas: um estudo comparativo entre 1984 e a série Black Mirror. Monografia (Graduação em Letras) - Universidade Federal do Rio Grande do Sul, Porto Alegre, 2018.

BETTIM, P. Percepções sobre o conceito de hipermodernidade a partir do uso das telas do episódio "Queda livre" do seriado Black Mirror. Monografia (curso de Relações Públicas) - Universidade Federal do Pampa, São Borja/RS, 2017.

BRANDÃO, Z.; BAETA, A. M. B.; ROCHA, A. D. C. O estado da arte da pesquisa sobre evasão e repetência no ensino de $1^{\circ}$. Grau no Brasil (1971-1981). Revista Brasileira de Estudos Políticos, Brasilia, v. 64, n. 147, p. 38-69, maio/ago. 1983.

BRANDÃO, Z. Evasão e repetência no Brasil: a escola em questão. Rio de Janeiro: Dois Pontos, 1986.

DEBORD, G. A sociedade do espetáculo. Rio de Janeiro: Contraponto, 1997.

HAN, B.-C. Psicopolitica: neoliberalismo e novas técnicas de poder. Lisboa: Relogio d'Água, 2015.

FAQUIN, C. B. Black Mirror: cinema, televisão ou produto híbrido? Dissertação (Mestrado em Comunicação e Linguagens) — Universidade Tuiuti do Paraná, Curitiba, 2018.

FERREIRA, N. S. A. As pesquisas denominadas "estado da arte". Educação \& Sociedade, Campinas/SP, v. 23, n. 79, p. 257-272, ago. 2002. 
FERREIRA, V. B. Fortes Serapio; SILVA, Miguel Rettenmaier da. O pós-humano em Black Mirror. IV Simpósio Internacional e VIII Simpósio Nacional de Literatura e Informática, Passo Fundo/RS, p. 1-10, 09 a 11 de nov. In: Anais... Passo Fundo, 2016.

FLUSSER, V. O mundo codificado: por uma filosofia do design e da comunicação. São Paulo: Cosac-Naif, 2007.

FLUSSER, V. O universo das imagens técnicas. São Paulo: Annablume, 2008.

JENKINS, H. Cultura da convergência. São Paulo: Aleph, 2009.

JENKINS, H.; GREEN, J.; FORD, S. Cultura da conexão: criando valor e significado por meio da mídia propagável. São Paulo: Aleph, 2014.

LAZZARIN, L. F. Pesquisa em educação. Santa Maria: Núcleo de Tecnologia Educacional NTE, 2017.

LEMOS, A. Isso (não) é muito Black Mirror: passado, presente e futuro das tecnologias de comunicação e informação. Salvador: EDUFBA, 2018.

LOPES, D. V. et al. "The entirehistoryofyou": cibercultura e memória. Mediação, Belo Horizonte/MG, v. 19, n. 24, p. 39-53, jan./jun. 2017

MAGNONI, A. F.; BRESSAN, D. L.; SILVA, S. R. Mídia e memória na primeira temporada de "Black Mirror". In: RENÓ, D. P. et al. (Orgs.). O audiovisual contemporâneo: mercado, educação e novas telas. Rosario: UNR Editora, Editorial de la Universidad Nacional de Rosario, 2016. p. 643-651.

MARCONI, M. de A.; LAKATOS, E. M. Metodologia científica. São Paulo: Atlas, 1991.

MATOS, B. A.; CARMO, L. J. O.; ASSIS, L. B. Quantas estrelas você vale? Uma análise da gamificação em um episódio da série Black Mirror. Farol, Belo Horizonte, v. 5, n. 13, p. 792-845, ago. 2018.

MENDES, C. M. Modalizações do fazer no episódio "Hino Nacional", do seriado Black Mirror. Significação, São Paulo/SP, v. 44, n. 48, p. 32-52, jul-dez. 2017.

NÓBREGA-THERRIEN, S. M.; THERRIEN, J. Trabalhos científicos e o estado da questão: reflexões teórico-metodológicas. Estudos em Avaliação Educacional, São Paulo, v. 15, n. 30, jul./dez. 2004.

OLIVEIRA, A. S. T.; NASCIMENTO, D. F.; SCHYRA, G. A. C. Da melancolia à ironia: o discurso dissimulado da contemporaneidade em Black Mirror. Texto Digital, Florianópolis, Santa Catarina, Brasil, v. 10, n. 2, p. 25-40, jul./dez. 2014.

PERNIOLA, M. O sex appeal do inorgânico. São Paulo, Studio Nobel, 2005.

PERNIOLA, M. L'estetica contemporânea. Bologna: Il Mulino, 2011. 
RIBEIRO, D. L. G. S.; CASTRO, R. C. A. M. Estado da arte, o que é isso afinal? III CONEDU - Congresso Nacional de Educação, Natal/RN, 05 a 07 out., 2016.

ROMANOWSKI, J. P.; ENS, R. T. As pesquisas denominadas do tipo "estado da arte" em educação. Diálogo Educ., Curitiba, v. 6, n. 19, p. 37-50, set./dez. 2006.

ROMANOWSKI, J. P. As licenciaturas no Brasil: um balanço das teses e dissertações dos anos 90. Tese (Doutorado em Educação) — Faculdade de Educação da Universidade de São Paulo, São Paulo/SP, 2002.

ROSA, M. S.; MEDEIROS, R. F. A extrapolação das relações virtuais em Black Mirror. Literatura e Autoritarismo, Santa Maria/RS, n. 20, p. 113-122, jul. 2017.

SANTAELLA, L. Culturas e arte dos pós-bumano. São Paulo: Paulus, 2008.

SANTOS, R. M. Estado da arte e história da pesquisa em educação estatística em programas brasileiros de pós-graduação. Tese (Doutorado em Educação) - Programa de Pós-graduação em Educação da Faculdade de Educação da Universidade Estadual de Campinas, Campinas/SP, 2015. 348 p.

SIBILIA, P. O show do eu: a intimidade como espetáculo. Rio de Janeiro: Nova Fronteira, 2008.

SILVA, E. L.; MENEZES, E. M. Metodologia da Pesquisa e Elaboração de Dissertação. Florianópolis: UFSC, 2005.

SOUZA, A. P.; GALEGO, L. G. C.; PEREIRA, F. L. Análise semiótica e do discurso no episódio "nosedive" da série Black Mirror: um olhar sobre a ética e as tecnologias da comunicação e informação. Revista Livre de Cinema, Curitiba, v. 5, n.4, p. 27-65, set.-dez. 2018 .

TISSERON, S. Intimité et Extimité. Communications, n. 88, p. 83-91, 2011.

TRENTO, F. B. Espelhos negros: mutações do desejo e da crítica na comunicação. Tese (Doutorado em Comunicação e Semiótica) - Pontifícia Universidade Católica de São Paulo, São Paulo, 2017.

TRENTO, F. B.; VENANZONI, T. S. Subjetividade, controle e ubiquidade midiática: o seriado Black Mirror. Intercom - XVIII Congresso de Ciências da Comunicação na Região Sudeste, Bauru/SP, 03 a 05 jul. 2013.

VINHAS, O. Direito e distopia tecnológica em Black Mirror: os discursos de ódio nas mídias digitais. In: Anais... III Seminário Internacional Imagens da Justiça, Currículo e Educação Jurídica, Pelotas/RS, 18 a 20 out. 2018.

VISCONTI, M. Black Mirror e a cegueira moral da modernidade. Temporalidades - Revista de História, Belo Horizonte, v. 9, n. 1, p. 143-166, jan./abr. 2017. 
XAVIER, A. S. C. S. Black Mirror - nosedive: a influência da midiatização nas práticas sociais. Monografia (Graduação em Publicidade e Propaganda) - Faculdade de Tecnologia e Ciências Sociais do Centro Universitário de Brasília, Brasília/DF, 2017.

RECEBIDO: $29 / 06 / 2019$

RECEIVED: 06/29/2019

RECIBIDO: 29/06/2019

APROVADO: 21/08/2019

APPROVED: 08/21/2019

APROBADO: 21/08/2019 